\title{
Switching strategy comparison of SP compensated inductive power transfer system
}

\author{
Ming-Tsung Tsai \\ Department of Electrical \\ Engineering, Southern Taiwan \\ University of Science and \\ Technology \\ Tainan, Taiwan \\ mttsai@stust.edu.tw
}

\author{
Ching-Lung Chu \\ Department of Electrical \\ Engineering, Southern Taiwan \\ University of Science and \\ Technology \\ Tainan, Taiwan
}

\author{
Ming-Dong Jiang \\ Department of Electrical \\ Engineering, Southern Taiwan \\ University of Science and \\ Technology \\ Tainan, Taiwan
}

\author{
Char-Yong Siow \\ Department of Electrical \\ Engineering, Southern Taiwan \\ University of Science and \\ Technology \\ Tainan, Taiwan
}

\begin{abstract}
This paper presents a wireless power transmission system which is consisted of a full-bridge converter, two resonance circuits and a diode rectifier to obtain the desired output voltage. The focused topology is based on SP compensation circuit, where $S$ denoted the primary coil is connected in series with the compensation capacitor, and $P$ denoted the secondary coil is connected in parallel with the compensation capacitor. In this research, the phase-shift based pulse width modulation (PWM) control and frequency modulation control are used to contrast the differences between these two methods. Both schemes include voltage loop and current loop control, so as to get the required performances. Finally, a prototype of DC $200 \mathrm{~V} / 48 \mathrm{~V}$ system with $500 \mathrm{~W}$ rating and $15 \mathrm{~cm}$ distance between two coils is set to verify the feasibility of the control idea.
\end{abstract}

Keywords-Wireless power transmission; pulse width modulation; frequency modulation.

\section{INTRODUCTION}

As the global environmental issues and the petroleum crisis, green energy technology is gradually taken seriously, while electric vehicle (EV) is one of the key techniques to the future development of green energy. Contrast with petroleum cars, EVs can reduce the carbon dioxide emissions, and is increasing in recent years and can be observed in the future to be substantial growth. However, electrical vehicles require external electric power to charging the battery, and nowadays most of charging methods rely on wires to charge, typically the wire will have metal contacts, which has the oxidation problem, and thereby may has sparks due to poor contact. Obviously, this situation would be dangerous to the users, where adopted the non-contact power transmission system would be prevent such a situation. In recent years, there are many researches focus on this type of non-contact power transmission issues.

There are many methods developed in the wireless power transmission, including electromagnetic induction, electromagnetic resonance, micro-wave conversion, and so on [1-4]. This paper focuses on the electromagnetic induction method whose resonant frequency is low, so that the circuit elements are easily obtained, but the transmission distance is more limited, usually about $0 \mathrm{~cm} \sim 20 \mathrm{~cm}$, and the coil coupling efficiency is relatively low, resulting in large magnetic flux leakages. Therefore, the circuit must be compensated by capacitors [5-10] to compensate for the reactive power generated by magnetic flux leakage.

In this paper, a SP (Series-Parallel) compensated inductive power transfer system with two modulation strategies is researched, including pulse width modulation and frequency modulation. The compensated network has been analyzed to obtain the required LC parameters, ensuring zero-voltage switching function for the full bridge converter. A $500 \mathrm{~W}$ prototype is built with $15 \mathrm{~cm}$ air gaps. Constant voltage control and constant current control have been tested to verify the design validity. This paper is organized as follows: Section II describes the system architecture. The parameters design is discussed in Section III. Section IV shows the experimental results. Finally, the conclusion is presented in Section V.

\section{SYSTEM ARCHITECTURE}

The researched system is depicted in Fig. 1. It includes a full-bridge converter, two loose coupled coils, and a rectifier. Two compensation capacitors in both circuits are shown as $\mathrm{C}_{\mathrm{S}}, \mathrm{C}_{\mathrm{P}}$. The control circuit is implemented by microcontroller with a wireless communication module.

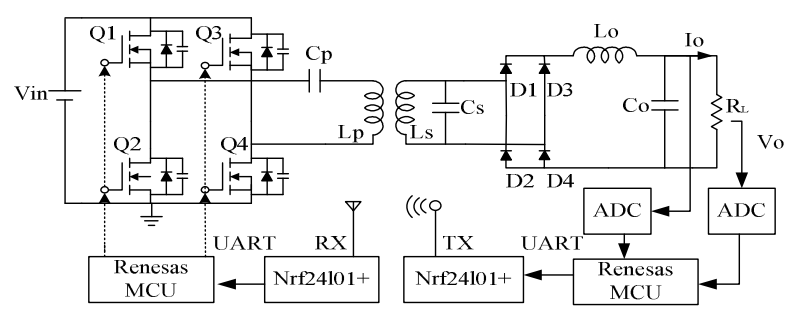

Fig. 1 The proposed inductive power transfer system. 


\section{A. TRANSMITTER and RECEIVER CIRCUIT}

The transmitter circuit is crucial for wireless power transmission. Fig. 1 exhibits the resonant capacitor of the transmitter circuit is connected in series with the primary coil, and the receiver circuit catches the energy from the coils by using the same resonant frequency, afterward through the rectifier circuit output to the load. The resonant capacitor of the receiver is connected in parallel with secondary coil.

Fig. 2(a) shows the simplified equivalent circuit of the receiver, where $L_{S}, C_{S}$ are connected in parallel to form a parallel resonant circuit, and $\mathrm{R}_{\mathrm{Load}}$ noted the reflected resistance from the rectifier output load.

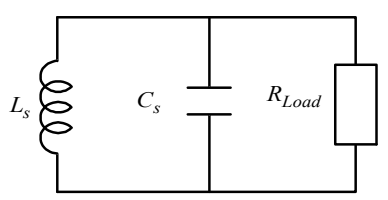

(a)

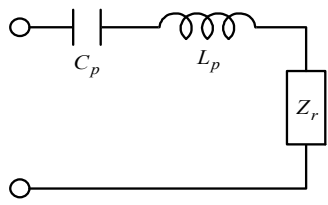

(b)
Fig. 2 The equivalent circuit of transmitter and receiver, (a) receiver, (b) transmitter.

\section{B. OPERATION PRINCIPLE}

From Fig. 2(a), the equivalent impedance $Z_{S}$ can be obtained:

$$
Z_{s}=j \omega L_{s}+\frac{1}{j \omega C_{s}+\frac{1}{R_{\text {Load }}}}
$$

Fig. 2(b) shows the simplified equivalent circuit of the transmitter, where $L_{p}, C_{p}$ are connected in series to form a series resonant circuit, and $\mathrm{Z}_{\mathrm{r}}$ noted the reflected impedance from the receiver, and can be shown in the following:

$$
\begin{gathered}
Z_{r}=\frac{\omega^{2} M^{2}}{Z_{s}} \\
R_{e} Z_{r}=\frac{\omega^{2} M^{2} R_{\text {Load }}}{R_{\text {Load }}^{2}\left(\omega^{2} C_{s} L_{s}-1\right)^{2}+\omega^{2} L_{s}^{2}} \\
I_{m} Z_{r}=\frac{-\omega^{3} M^{2}\left(C_{s} R_{\text {Load }}^{2}\left(\omega^{2} C_{s} L_{s}-1\right)+L_{s}\right)}{R_{\text {Load }}^{2}\left(\omega^{2} C_{s} L_{s}-1\right)^{2}+\omega^{2} L_{s}^{2}} \\
\omega_{r}=\frac{1}{\sqrt{\mathrm{L}_{\mathrm{s}} \mathrm{C}_{\mathrm{s}}}}
\end{gathered}
$$

If the full-bridge converter is switching at the same frequency as the receiver resonant frequency, then the reflected impedance can be simplified as follows:

$$
\begin{aligned}
& R_{e} Z_{r}=\frac{M^{2} R_{\text {Load }}}{L_{s}^{2}} \\
& I_{m} Z_{r}=-\frac{\omega_{r} M^{2}}{L_{s}}
\end{aligned}
$$

From Fig. 2(b), the equivalent impedance $Z_{t}$ can be obtained as follows:

$$
Z_{t}=\frac{1}{j \omega C_{p}}+j \omega L_{p}+Z_{r}
$$

The real part of the impedance determines actually the power transfer to the transmitter, and the imaginary part determines the reactive power flow in the transmitter. The best way is to operate the switching frequency in the transmitter resonant frequency so as to achieve the load reactance is zero to eliminate the ineffective reactive power, ensuring maximum power transfer, That is

$$
I_{m} Z_{t}\left(\omega=\omega_{r}\right)=0
$$

Thus the primary side capacitance $C_{p}$ value can be chosen as follows:

$$
C_{p}=\frac{1}{\omega_{r}^{2}\left(L_{p}-M^{2} / L_{s}\right)}
$$

\section{PARAMETERS DESIGN}

Fig. 3 shows the coupling coil diagram. This paper adopts the same coil radius of $25 \mathrm{~cm}$ for both transmitter and receiver, and the coil parameters are listed in Table 1.

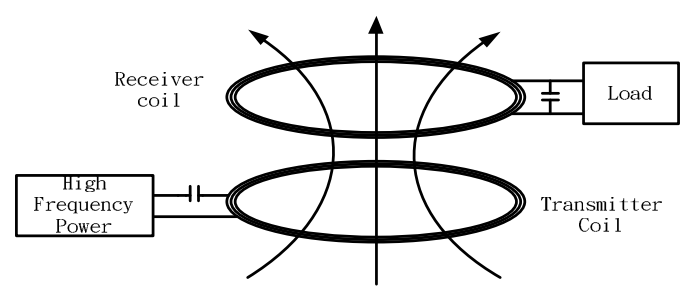

Fig. 3 Coupling coil diagram.

Table1. Coil parameters

\begin{tabular}{|c|c|c|}
\hline & Primary Coil & Secondary Coil \\
\hline Inside diameter $r(\mathrm{~cm})$ & 25 & 25 \\
\hline Winding depth $d(\mathrm{~cm})$ & 8 & 4 \\
\hline Coil turns $N$ & 16 & 4 \\
\hline Coil inductance $\mathrm{L}_{\mathrm{p}} / \mathrm{L}_{\mathrm{s}}(u H)$ & 262 & 19.7 \\
\hline Coupling coefficient $k$ & \multicolumn{2}{|c|}{0.24} \\
\hline Mutual inductance $\mathrm{M}(u H)$ & \multicolumn{2}{|c|}{17.4} \\
\hline Distance of two coils $(\mathrm{cm})$ & \multicolumn{2}{|c|}{15} \\
\hline
\end{tabular}

As the inductance is $262 \mathrm{uH}$ for the transmitter coil, and a resonance frequency range of $40 \mathrm{kHz} \sim 50 \mathrm{kHz}$ is chosen in this paper, therefore, the compensation capacitance obtained from (10) is shown as follows:

$$
C_{p_{(40 \mathrm{kHz})}}=64.19 \times 10^{-9}(\mathrm{~F}), C_{p_{(50 \mathrm{kHz})}}=41.08 \times 10^{-9}(\mathrm{~F})
$$

For a resonant frequency range from $40 \mathrm{kHz}$ to 50 $\mathrm{kHz}$, it is clear that the primary compensation capacitance is between $41.08 \mathrm{nF}$ and $64.19 \mathrm{nF}$. In this paper, a capacitance of $44 \mathrm{nF}$ is selected, and the coil inductance is $262 \mu \mathrm{H}$, thus the resonant frequency can be shown as follows:

$$
f_{r}=\frac{1}{2 \pi \sqrt{L_{p} C_{p}}}=\frac{1}{2 \pi \sqrt{262 \times 10^{-6} \times 44 \times 10^{-9}}}=46\left(k H_{Z}\right)
$$


Generally, the secondary resonance frequency is designed near to primary resonance frequency of 46 $\mathrm{kHz}$. Therefore, the secondary compensation capacitance is given by:

$C_{s}=\frac{1}{\omega_{r}{ }^{2} L_{s}}=\frac{1}{\left(2 \pi \times 46 \times 10^{3}\right)^{2} \times 19.7 \times 10^{-6}}=607 \times 10^{-9}(\mathrm{~F})$

Fig. 4 shows the voltage gain plot of the researched inductive power transfer system with different load cases. It shows the output gain of SP topology has frequency bifurcate phenomenon for light load, such as $\mathrm{R}_{\mathrm{L}}=12 \Omega$ related to $\mathrm{R}_{\mathrm{L}}=32 \Omega$, and it should be avoided in the use of frequency modulation control strategy. Thus the switching frequency must be higher than the bifurcate frequency to regulate the output voltage, and this will result in an adverse effect for the system efficiency. This paper focuses on the influence due to switching strategies.

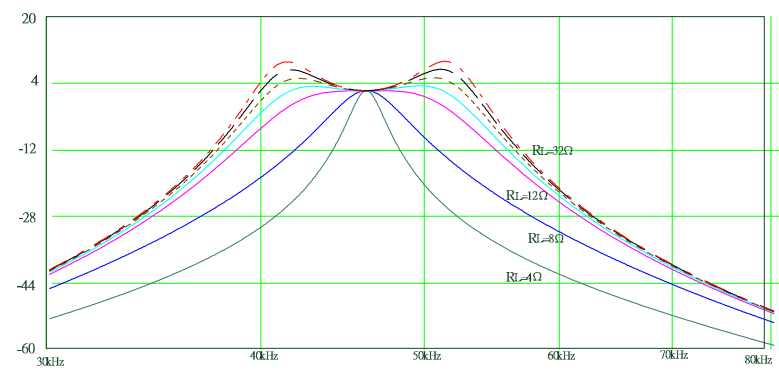

Fig. 4 Voltage gain plot of the researched SP topology.

Fig. 5 shows the case of phase shift control based pulse-width modulation, and Fig. 6 shows the case of frequency modulation based control method.

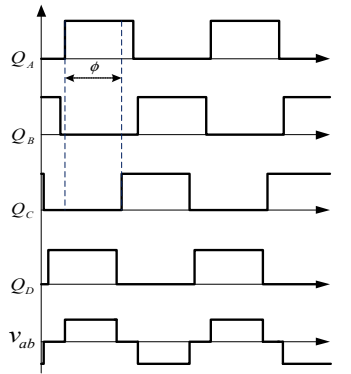

Fig. 5 Phase-shift PWM. modulation.

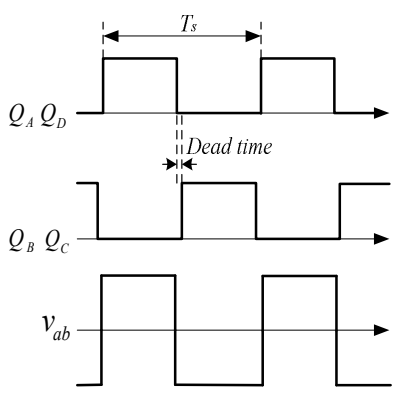

Fig. 6 Frequency

Fig. 7 shows the relationship of switching frequency and resonant frequency for the variable frequency modulation. The switching frequency $f_{s}$ is shifted from the resonance frequency $f_{r}$ to get the required output energy, and $f_{s}$ will shift close to $f_{r}$ when the load is heavy, which is shown as Fig. 7(a), otherwise $f_{s}$ is shifted away from $f_{r}$, such as Fig. 7(b).

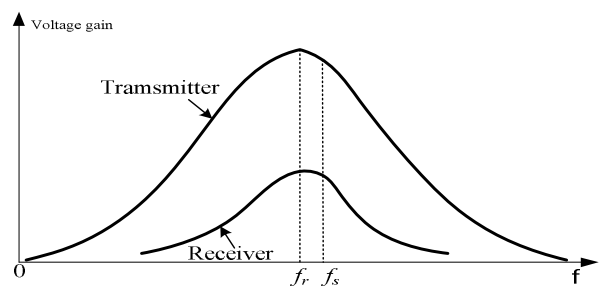

Fig. 7(a) The relationship between $f_{s}$ and $f_{r}$ for frequency modulation at heavy load case.

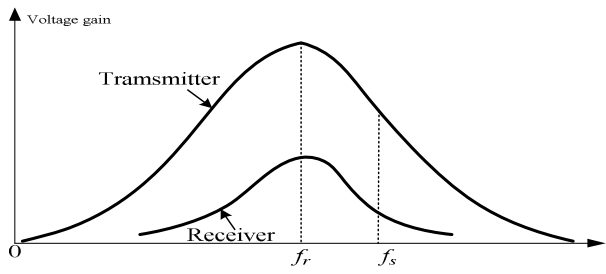

Fig. 7(b) The relationship between $f_{s}$ and $f_{r}$ for frequency modulation at light load case.

\section{IV.EXPERIMENTAL RESULTS} 2.

The prototype circuit parameters are shown in Table

Tab. 2 Wireless power transmission parameters

\begin{tabular}{|l|l|}
\hline Electrical Parameters & Value \\
\hline Input voltage $\mathrm{V}_{\text {in }}(\mathrm{V})$ & 200 \\
\hline Output voltage $\mathrm{V}_{\text {out }}(\mathrm{V})$ & 48 \\
\hline Output current $\mathrm{I}_{\text {out }}(\mathrm{A})$ & 10.6 \\
\hline Primary coil inductance $L_{P}(u H)$ & 264 \\
\hline Secondary coil inductance $L_{S}(u H)$ & 19.7 \\
\hline Primary capacitor $C_{P}(n F)$ & 48 \\
\hline Secondary capacitor $C_{S}(n F)$ & 607 \\
\hline Load $R_{L}(\Omega)$ & $4.6 \sim 23$ \\
\hline Switching frequency $(\mathrm{Hz})$ & $51 \mathrm{k} \sim 60 \mathrm{k}$ \\
\hline
\end{tabular}

\section{A. FREQUENCY MODULATION STRATEGY}

Fig. 8 shows the transmitter input voltage and current for the frequency modulation method. Fig. 8(a) shows the case of $509 \mathrm{~W}$ switched at $51 \mathrm{kHz}$, and Fig. 8 (b) shows the case of $102 \mathrm{~W}$ switched at $57.8 \mathrm{kHz}$. It shows the full-bridge converter supplies an inductance load, thus the four switches have the performance of zero-voltage switching function. Fig. 9 shows a case of power switch state at $102 \mathrm{~W}$.

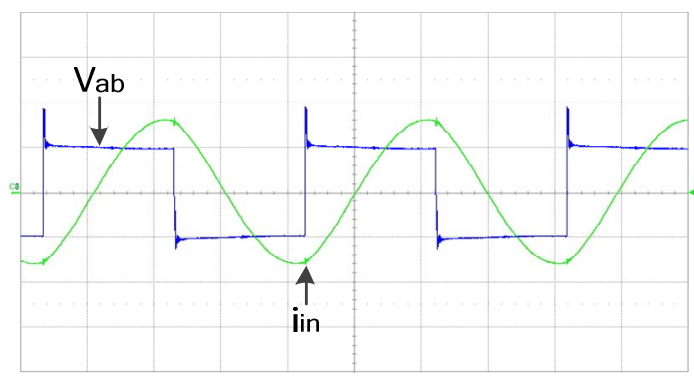

$\mathrm{V}_{\mathrm{ab}}: 200 \mathrm{~V} / \mathrm{div} ; \mathrm{i}_{\text {in }}: 10 \mathrm{~A} / \mathrm{div}$

Fig. 8(a) The transmitter input voltage and current in the case of $509 \mathrm{~W}$.

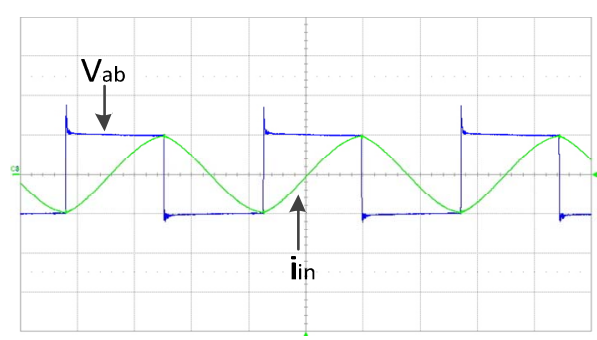

$v_{a b}: 200 \mathrm{~V} / \mathrm{div} ; i_{\text {in }}: 10 \mathrm{~A} / \mathrm{div}$

Fig. 8(b) The transmitter input voltage and current in the case of $102 \mathrm{~W}$. 


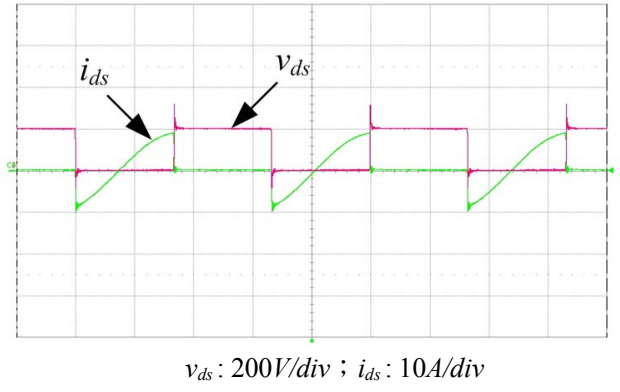

Fig. 9 Q1 switching waveform at $102 \mathrm{~W}$.

The transmitter and receiver voltages and currents are depicted in Fig. 10, where Fig. 10(a) shows the transmitter, and Fig. 10(b) shows the receiver. The power is about $102 \mathrm{~W}$.

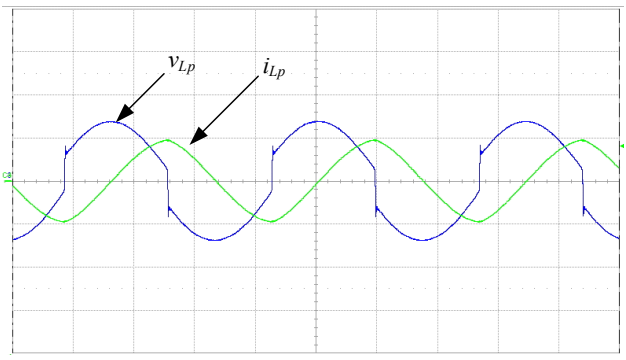

$$
v_{L p}: 500 \mathrm{~V} / d i v ; i_{L p}: 10 \mathrm{~A} / \mathrm{div}
$$

Fig. 10(a) The voltage and current waveforms of the transmitter for $102 \mathrm{~W}$ output.

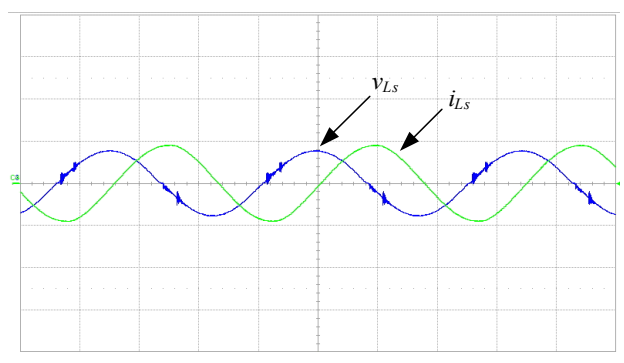

$v_{L s}: 100 V / d i v ; i_{L s}: 20 \mathrm{~A} / d i v$

Fig. 10(b) The voltage and current waveforms of the receiver for $102 \mathrm{~W}$ output.

The performance of constant voltage and constant current control is exhibited in Fig.11, where $\mathrm{R}_{\mathrm{L}}$ is 4.6 ohms in constant current mode, and is adjusted to 23 ohms to raise the output voltage $V_{0}$ to $48 \mathrm{~V}$, and maintains at this value so as to achieve the constant voltage mode function. Fig. 12 shows the system efficiency for the frequency modulation scheme.

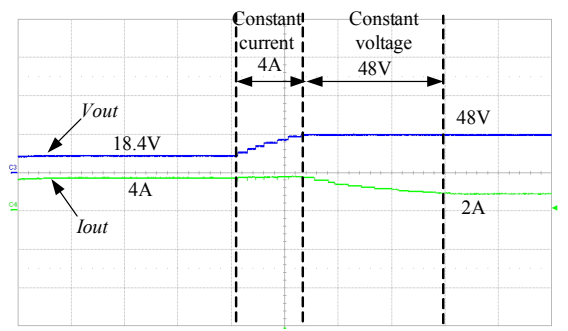

$$
V_{\text {out }}: 50 \mathrm{~V} / \mathrm{div} ; I_{\text {out }}: 5 \mathrm{~A} / \mathrm{div}
$$

Fig. 11 Constant voltage and constant current regulation.

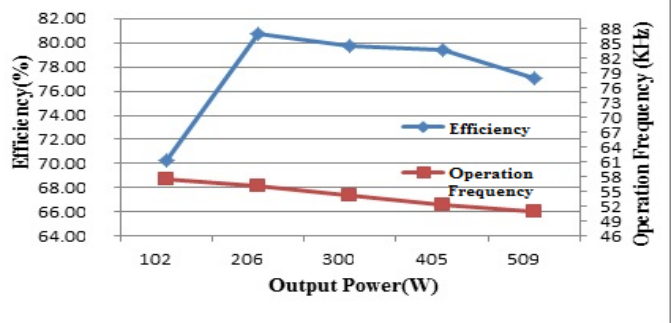

Fig.12 Efficiency for frequency modulation strategy.

\section{B. PHASE-SHIFT PWM STRATEGY}

Fig. 13 shows the transmitter input voltage and current for the phase-shift PWM control method. Fig. 13(a) shows the case of 476W, and Fig. 13(b) shows the case of $101 \mathrm{~W}$. The switching frequency is $48.8 \mathrm{kHz}$.

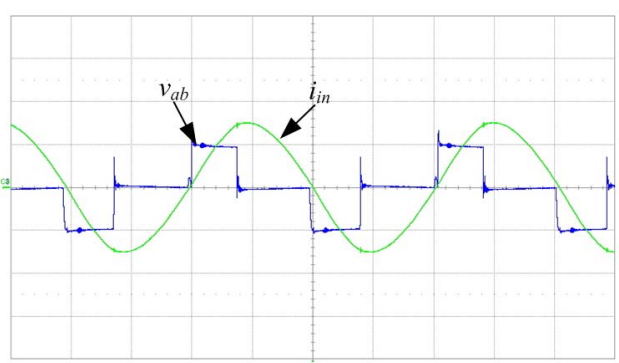

$v_{a b}: 200 V / d i v ; i_{i n}: 10 \mathrm{~A} / d i v$

Fig. 13(a) The transmitter input voltage and current in the case of $476 \mathrm{~W}$.

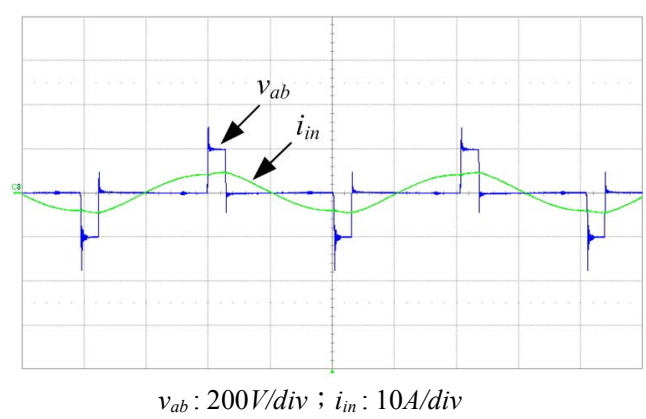

Fig. 13(b) The transmitter input voltage and current in the case of $101 \mathrm{~W}$.

The voltage and current waveforms of the transmitter and receiver are depicted in Fig. 14, where Fig. 14(a) shows the transmitter, and Fig. 14(b) shows the receiver. Fig. 15 shows the efficiency in this modulation scheme.

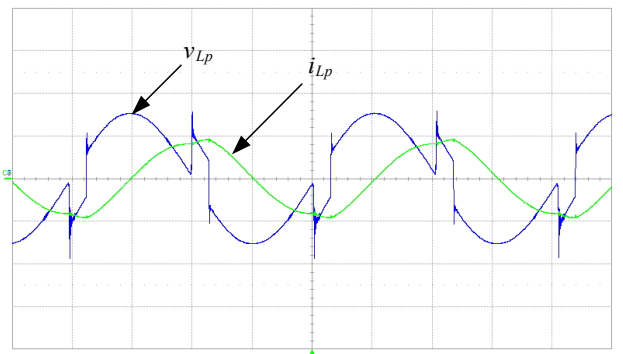

$v_{a b}: 200 V / d i v ; i_{i n}: 10 A / d i v$

Fig. 14(a) The voltage and current waveforms of the transmitter for $101 \mathrm{~W}$ load output. 


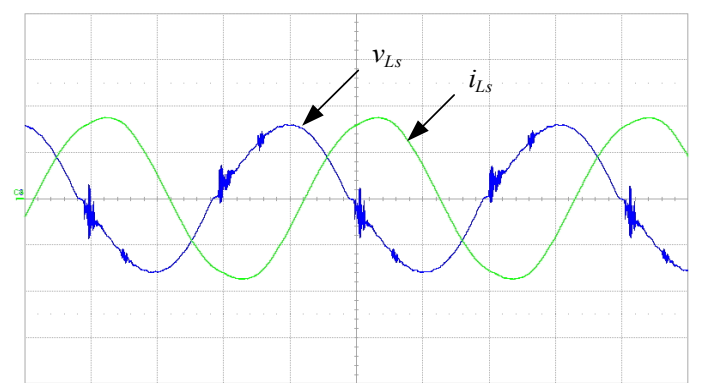

$v_{L s}: 50 \mathrm{~V} / \mathrm{div} ; i_{L s}: 10 \mathrm{~A} / \mathrm{div}$

Fig. 14(b) The voltage and current waveforms of the receiver for $101 \mathrm{~W}$ load output.

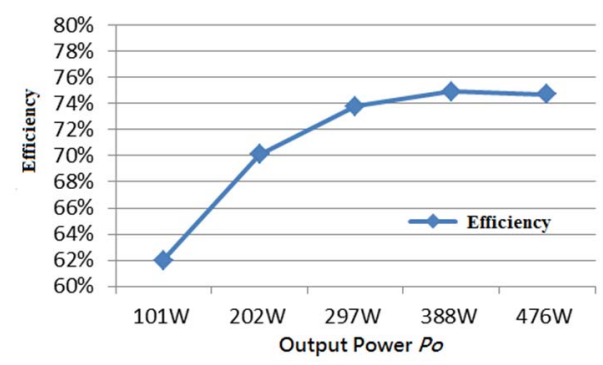

Fig.15 Efficiency for phase-shift PWM strategy.

\section{CONCLUSION}

This paper is to explore the non-contact power transmission system with two modulation schemes, including phase-shift PWM method and frequency modulation method. Both control algorithms are consisted of voltage loop and current loop. The experimental results show the frequency modulation has better performance for the efficiency even though the switching frequency is higher than the phase-shift PWM method. It also shows the phase-shift PWM method will induce large harmonics in the terminal voltages of transmitter and receiver.

\section{ACKNOWLEDGMENT}

This work has been supported by Ministry of Science and Technology, Taiwan, R. O. C. under research project MOST 105-2221-E-218-025.

\section{REFERENCES}

[1] C. Duan, C.Jiang, A.Taylor, and K. Bai, "Design of A ZeroVoltage-Switching Large-Air-Gap Wireless Charger with Low Electrical Stress for Plugin Hybrid Electric Vehicles,' IEEE ITEC, pp. 1-5, June 2013.

[2] Kurs, A. Karalis, R. Moffatt, J. D. Joannopoulos, F. Peter, and S. Marin, "Wireless Power Transfer via Strongly Coupled Magnetic Resonances," in Proc. Science Express, Vol. 317, No. 5834, pp. 83-86, Jun. 2007.

[3] J. L. Li, "Wireless power transmission: State-of-the-arts in technologies and potential applications," in Proc. IEEE APMC, pp. 86-89, Dec. 2011.

[4] G. A. J. Elliott, S. Raabe, G. A. Covic, and J. T. Boys, "Multiphase Pickups for Large Lateral Tolerance Contactless Power-Transfer Systems," IEEE Trans. Power Electron, Vol. 57, No. 5, pp. 1590-1598, May 2010

[5] X. Ren, Q. Chen, L. Cao, X. Ruan, S. C. Wong, and C. K. Tse, "Characterization and Control of Self-Oscillating Contactless Resonant Converter with Fixed Voltage Gain," IEEE Power Electronics and Motion Control Conference, vol. 3, pp. 1822-1827, June.2012.

[6] J. Hou, Q. Chen, S. C. Wong, C. K. Tse, and X. Ruan, "Analysis and Control of Series/Series-Parallel Compensated Resonant Converter for Contactless Power Transfer," IEEE Journal of Emerging and Selected Topics in Power Electronics, Vol. 3, No. 1, pp. 124-136, March 2015

[7] R. Nozawa, R. Kobayashi, H. Tanifuji, Y. Kaneko, and S. Abe, "Excitation System by Contactless Power Transfer System with the Primary Series Capacitor Method," IEEE IPEC-Hiroshima 2014 - ECCE ASIA, pp. 11151121, May 2014

[8] Z. Huang, S. C. Wong, and C. K. Tse, "Design Methodology of a Series-Series Inductive Power Transfer System for Electric Vehicle Battery Charger Application," IEEE Energy Conversion Congress and Exposition, pp. 1778-1782, Sept. 2014.

[9] D. T. G. Xavier, V. Javier, and R. S. Pedro, "Design, implementation issues and performance of an inductive power transfer system for electric vehicle chargers with series-series compensation," IET Power Electronics, Vol. 8, No. 10, pp. 1920-1930, Oct. 2015.

[10] G. RIturaj, E. R. joy, B. K. Kushwaha, and P. Kumar, "Analysis and Comparison of Series-Series and SeriesParallel Topology of Contactless Power Transfer Systems," IEEE TENCON 2014, pp.1-6, Oct. 2014. 